\title{
Relationship among Health Related Quality of Life, Quality of Sleep, and Oral Health Condition
}

\author{
Miki Sato1, Arisa Kurokawa², Hiroko Sugimoto², \\ Yuko Yasuhara ${ }^{3}$, Hiromi Nakae 4 , Yukari Shinohara ${ }^{5}$, \\ Tetsuya Tanioka ${ }^{3}$, Hiroki Iga6, Daisuke Hinode', \\ Yoshihiro Suzuki 7 , Souichi Honda7, Rozzano Locsin ${ }^{3}$ \\ ${ }^{1}$ Faculty of Nursing, Kochi University, Kochi, Japan \\ ${ }^{2}$ Graduate School of Health Sciences, Tokushima University, Japan \\ ${ }^{3}$ Department of Nursing, Institute of Biomedical Sciences, Tokushima University, Tokushima, Japan \\ ${ }^{4}$ Department of Oral Health Sciences, Faculty of Health and Welfare, Tokushima Bunri University, Tokushima, Japan \\ ${ }^{5}$ Tokushima Municipal Hospital, Tokushima, Japan \\ ${ }^{6}$ Department of Oral Science, Institute of Biomedical Sciences, Tokushima University, Graduate School, Tokushima, Japan \\ ${ }^{7}$ Minami Municipal Hospital, Tokushima, Japan \\ Email: m-sato@kochi-u.ac.jp
}

How to cite this paper: Sato, M., Kurokawa, A., Sugimoto, H., Yasuhara, Y., Nakae, H., Shinohara, Y., Tanioka, T., Iga, H., Hinode, D., Suzuki, Y., Honda, S. and Locsin, R. (2018) Relationship among Health Related Quality of Life, Quality of Sleep, and Oral Health Condition. Health, 10, 204-214. https://doi.org/10.4236/health.2018.102017

Received: January 27, 2018

Accepted: February 25, 2018

Published: February 28, 2018

Copyright $\odot 2018$ by authors and Scientific Research Publishing Inc. This work is licensed under the Creative Commons Attribution International License (CC BY 4.0).

http://creativecommons.org/licenses/by/4.0/

\section{c) (i) Open Access}

\begin{abstract}
Japan's aging rate (ratio of elderly aged 65 and older to total population) has exceeded $20 \%$. The aim of this study was to clarify the relationships between Health Related Quality of Life (HRQOL), Body Mass Index (BMI), and sleep quality. Subjects were 51 adults over 55 years old with chronic disease who living in the community. Instruments and structured interviews were used giving due consideration to privacy. Interviews were conducted within $10-20$ minutes at the out-patient department. The evaluation instruments included body-mass index, Pittsburgh Sleep Quality Index (PSQI), HRQOL, and OHIP-14. A significant positive correlation $(\rho=0.321, \mathrm{p}<0.05)$ between PSQI and QOL (OHIP-14) scores was confirmed with sleep quality being lower with lower QOL scores. A negative correlation $(\rho=-0.339, \mathrm{p}<0.05)$ between physical health component summary scores (PCS) and mental health component summary scores (MCS) of HRQOL was confirmed, demonstrating that PCS was low, and the level of MCS was high. Sleep quality was found lower among those with lower oral health-related QOL scores. Moreover, in subjects with lower MCS scores, the PCS scores were found to be higher. Accordingly, it was considered appropriate that dental treatment and care, support the maintenance of activities and sleep, and mental health promotion which are likely requisites critical for elderly persons' maintenance of independent lifestyles in their familiar community.
\end{abstract}




\section{Keywords}

Health Related Quality of Life, Body-Mass Index, Quality of Sleep, Oral Condition, Over 55 Years Old, Middle Aged and Older Japanese Adults

\section{Introduction}

According to a survey by the Cabinet Office of the Government of Japan, among the population in 2017, the elderly population of 65 years of age and over was 35 million, exceeding $27 \%$ of the total population in 2017 [1]. Since the overall population is also declining due to the low birth rate, it is estimated that in 2065, one of every 2.6 people in Japan will be 65 years of age and older. Against this background, it is necessary for more elderly people to be able to lead a happy and healthy life in the community by maintaining their quality of life (QOL), even if they are suffering from chronic diseases. In doing so, this will help extend longevity and lead to cost control for medical and long-term care.

In general, a person with at least 20 teeth is considered to have sufficient chewing ability for food intake and is able to lead a satisfactory dietary life [2]. In Dental Diseases Survey in 2017 in Japan, it was found that the proportion of 80 -year-olds having at least 20 teeth was about $52 \%$, which was higher than in 2013, and this is due to an increased awareness of the importance of oral care [3]. However, the number of existing teeth tends to decrease after age 55. In particular, in the elderly person, a decrease in the number of existing teeth due to aging causes a decline in chewing ability, which in turn leads to a decrease in nutrient intake [4] [5]. Associations between chewing ability with activities of daily living (ADL) [6], cognitive function [7], and QOL [8] [9] have also been reported.

Epidemiological studies with elderly person 80 years and older have also reported that people with fewer missing teeth and adequate chewing ability had better QOL, higher vitality, and superior motor and audiovisual function [10] [11].

In addition, it has been reported that fall risk is higher for elderly people who have 19 or fewer natural teeth and do not use dentures [12]. Inability to perform sufficient oral care because of age-related decline in immune function and a decrease in ADL results in an increase in opportunistic oral pathogens [13]. Cleaning the oral cavity through appropriate oral care is thought to be associated with a reduced risk of opportunistic infectious diseases, thereby maintaining the health of the person [14]. Previous studies have reported on the association between age-related chewing ability and health status [15] [16], that the number of remaining teeth and the presence or absence of denture use, necessity of dental treatment, and awareness of dry mouth are known to affect oral health-related QOL [17].

Additionally, aging also affects the sleep-wake rhythms [18]. In elderly people, 
declines in quality of sleep, such as low number of sleep efficiency and irregular awakening; and changes in sleep rhythm, such as less total sleep time, early-morning awakening, and daytime sleepiness have been reported [18]. The prevalence of insomnia increases after the age of 50 [19]. According to studies on the prevalence of insomnia, the frequency of irregular awakening and early-morning awakening in elderly was about two times that in young people [20] [21]. Sleep irregularity in elderly people causes declines in social and physical functioning [22] [23] and reduces opportunities for maintaining appropriate sleep-wake rhythm, through daily activity, exposure to light, and exercise [24]. In the rapidly aging society of Japan, improving the sleep quality of the elderly may likely be an important intervention for sustaining independent living [25].

Although various factors for maintaining health in elderly people can be considered, it is also important to determine factors for a long and happy life by preserving QOL of elderly people living in the community.

The aim of this study was to clarify the relationship between health-related QOL and sleep quality of older people age 55 years and older, focusing on oral hygiene and oral health-related QOL and chronic disease.

\section{Methods}

\subsection{Subjects}

Subjects selected were those in the outpatient department at A Hospital. These subjects met the inclusion criteria: Ability to complete a questionnaire; 55 years old and older, and with chronic disease who live in the community. Exclusion criteria included those with dementia, severe heart disease, and those under treatment for cancer disease.

\subsection{Survey Period}

The survey was conducted from July 2016 to August 2017.

\subsection{Measures}

The target setting for this survey was a suburban area with an elderly population of more than $40 \%$. In this survey, the researchers conducted structured interviews using a questionnaire that included the following data:

1) Basic information

The subjects were asked about their attributes (age, sex, height, and body weight).

2) Sleep quality

The sleep QOL was subjectively assessed using the Japanese version of the Pittsburgh Sleep Quality Index (PSQI-J) [26]. The PSQI consists of seven subscales: sleep quality, sleep latency, sleep duration, sleep efficiency, sleep disturbances, use of sleeping medication, and daytime dysfunction. The PSQI has a maximum overall score of 21, with higher scores indicating sleep disorders. Using a cut-off score of 6 [27], any score higher than this was considered as indicating 
low sleep quality.

3) Health-related QOL

Health-related QOL was assessed using the SF- ${ }^{\text {rx }}$ Health Survey (Japanese version) [28]. The subject's HRQOL using the Medical Outcomes Study 8-item Short Form Health Survey for Japanese was determined. SF-8 was evaluated with 8 subscales which consists of "physical functioning (PF)", "role physical (RP)", "bodily pain (BP)", "general health (GH)", "vitality (VT)", "social functioning (SF)", "role emotional (RE)", and "mental health (MH)". These subscales were summarized as the "physical health component summary score (PCS)" and "mental health component summary score (MCS)". The higher the score, the better the health-related QOL. Any score higher than the cut-off score of 50 was considered as indicating high QOL.

4) Oral health-related QOL

Oral health-related QOL [29] was assessed using the Japanese version of the Short-form Oral Health Impact Profile (OHIP-14) [30]. The OHIP-14 is considered to be a highly reliable and valid instrument [31]. The OHIP-14 comprises seven dimensions of impact: functional limitation, pain, psychological discomfort, physical disability, psychological disability, social disability, and handicaps. The overall maximum score is 56, with lower scores denoting better oral health-related QOL. Any score higher than the cut-off score of 14 was taken as an indication of poor oral health-related QOL.

5) Eichner's classification

Oral condition was checked by a dentist and a dental hygienist. Support areas in the upper and lower jaws for the remaining teeth were evaluated. The premolar and molar parts on the left and right sides were divided into four blocks of occlusal support, and depending on the presence or absence of stable occlusal support in each of the areas, three classifications were made: A denoting the presence of occlusal support in all four blocks, B denoting missing support in one or all blocks, and $\mathrm{C}$ denoting a total absence of occlusal support. Although in Eichner's classification [32], there are a total of 10 categories based on occlusal support conditions (A1-3, B1-4, and C1-3). In this study, only three categories were used, A, B, C based on dental occlusal support. Therefore, the categories did not include to the correlational analysis.

\subsection{Data Analysis}

Descriptive analysis was performed, and the Spearman's rank correlation coefficient was used to determine the correlation of each of the identified parameters. A statistical software program (SPSS $20.0 \mathrm{~J}$ ) was used. The significance level was set at probability less than 0.05 .

\subsection{Ethical Considerations}

The data were managed according to the Private Information Protection Law, with approval by Tokushima University Hospital Ethics Board (Approval number 
2648). They were assured that their personal information would be protected, reported in aggregate, and used only for research purposes.

\section{Results}

There were 51 subjects (26 males, 25 females) who consented to an oral examination (Table 1 ). The subjects had a mean age of $74.92 \pm 7.71$ years (range: $57-$ 87 ), and an average BMI of $23.93 \pm 5.10 \mathrm{~kg} / \mathrm{m}^{2}$ (range: $16.9-47.0$ ).

The mean scores for the measures were as follows: PSQI: $6.29 \pm 3.50$ points (range: 1 - 14), SF-8 (PCS): $46.84 \pm 7.42$ points (range: 21.96 - 56.31), SF-8 (MCS): $52.88 \pm 5.74$ points (range: $31.89-66.66$ ), and OHIP-14: $4.06 \pm 4.33$ points (range: 0 - 16).

In the sleep quality evaluation using the PSQI-J, poor sleep quality indicated by a score of more than 6 was observed in 25 (49\%) subjects.

In the SF-8 evaluation, 20 (39.2\%) subjects were found to have a physical health component summary score (PCS) of more than 50 (good health). As for the mental health component score (MCS), 40 (78.4\%) subjects obtained scores above 50. In the OHIP-14 evaluation, only 2 (3.9\%) subjects had scores above 14 .

In the evaluation of occlusal support level using Eichner's classification index, there were 23 subjects (45.1\%) in category C (complete absence of support), followed by 17 (33.3\%) in category B (partially or completely missing support in four areas), and 11 (21.6\%) in category A (presence of support in all four areas).

Table 1. Summary of all participants measured item values $(n=51)$.

\begin{tabular}{|c|c|c|c|}
\hline Measured items & Minimum & Maximum & Mean \pm SD \\
\hline Age & 57 & 87 & $74.92 \pm 7.71$ \\
\hline Female sex-no./total no. (\%) & \multicolumn{2}{|c|}{$25 / 51(49.0 \%)$} & \\
\hline BMI: Body Mass Index $\left(\mathrm{kg} / \mathrm{m}^{2}\right)$ & 16.90 & 47.00 & $23.93 \pm 5.10$ \\
\hline PSQI: Pittsburgh Sleep Quality Index (points) & 1 & 14 & $6.29 \pm 3.50$ \\
\hline PSQI $\geq 6$ no./total no. (\%) & \multicolumn{2}{|c|}{$25 / 51(49.0 \%)$} & \\
\hline PCS: Physical Component Summary (points) & 21.96 & 56.31 & $46.84 \pm 7.42$ \\
\hline PCS $\geq 50$ no./total no. (\%) & \multicolumn{2}{|c|}{$20 / 51(39.2 \%)$} & \\
\hline MCS: Mental Component Summary (points) & 31.89 & 66.66 & $52.88 \pm 5.74$ \\
\hline MCS $\geq 50$ no./total no. (\%) & \multicolumn{2}{|c|}{$40 / 51(78.4 \%)$} & \\
\hline OHIP-14: Short-form oral health impact profile (points) & 0 & 16 & $4.06 \pm 4.33$ \\
\hline OHIP-14 $\geq 14$ no./total no. (\%) & \multicolumn{2}{|c|}{$2 / 51(3.9 \%)$} & \\
\hline${ }^{*}$ Eichner's A, B or C categories & \multicolumn{3}{|c|}{$11(21.6 \%), 17(33.3 \%)$ or $23(45.1 \%)$} \\
\hline
\end{tabular}

*Eichner's classification is an evaluation result not including dentures. Schematic representation of Eichner's index. A1: complete dentition. A2: missing teeth in one arch. A3: missing teeth in both arches. Category B contains 1-3 OSZs or contacts in the anterior area only. B1: 3 OSZs. B2: 2 OSZs. B3: 1 OSZ. B4: contacts in the anterior area only. Category C does not have any OSZs. C1: teeth in both arches. C2: teeth in one arch. C3: edentulous. For this study, the subjects were adults who were over 55 years and with chronic disease. The proportion of elderly people living in the target area for this study exceeded $40 \%$ which is relatively high as compared to the Japanese national average of $26.7 \%$. 
Next, the relationship among age, BMI, PSQI, OHIP-14, PCS, and MCS scores are shown in Table 2. However, there was no association between age and BMI.

A significant positive correlation $(\rho=0.321, p<0.05)$ between the PSQI and the OHIP-14 scores, and a negative correlation $(\rho=-0.339, p<0.05)$ between the PCS and the MCS were confirmed (Figure 1).

\section{Discussion}

In the target population of middle aged and older Japanese adults in this study, the age range was $57-87$ years, with a mean of $74.92 \pm 7.71$ years.

Poor sleep quality has been reported even in healthy elderly people [33], “The second term of National Health Promotion Movement in the twenty first century (Health Japan 21) [34]" from 2013 to 2022 fiscal year, dental and oral health has been added to the list of targets for improvement in lifestyle habits and social environments, drawing further attention to the relationship between oral conditions and general health.

Table 2. Relationship among oral health related quality of life and quality of sleep $(n=51)$.

\begin{tabular}{cccccc}
\hline & Age & BMI & PSQI & OHIP-14 & PCS \\
\hline Age & - & - & - & - & - \\
(1) BMI & -0.246 & - & - & - & - \\
(2) PSQI & -0.059 & 0.020 & - & - & - \\
(3) OHIP-14 & -0.234 & 0.146 & $0.321^{*}$ & - & - \\
(4) PCS & -0.023 & -0.164 & 0.089 & 0.031 & - \\
(5) MCS & 0.202 & 0.051 & -0.222 & -0.054 & $-0.339^{*}$
\end{tabular}

Notes: Spearman's rank correlation coefficient. $p<0.05$. Abbreviation: (1) BMI; Body Mass Index, (2) PSQI; Pittsburgh Sleep Quality Index, (3) OHIP-14; Short-form oral health impact profile, (4) PCS: Physical Component Summary, (5) MCS: Mental Component Summary.
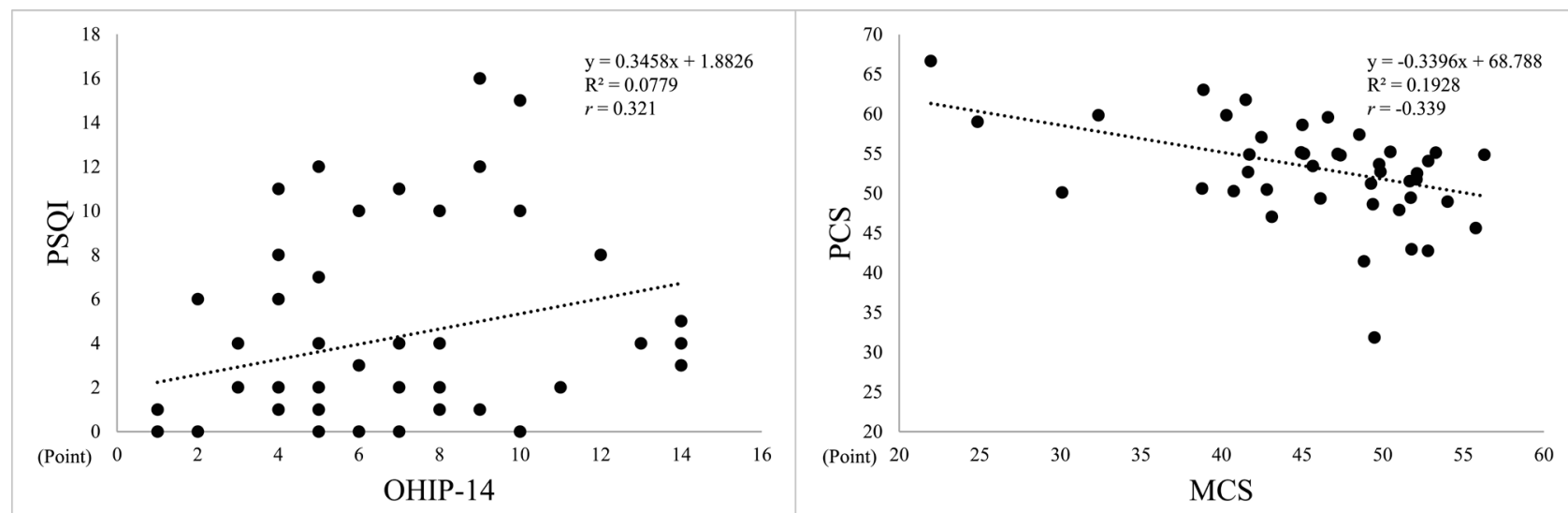

PSQI: Pittsburgh Sleep Quality Index, OHIP-14; Short-form oral health impact profile, PCS: Physical Component Summary, MCS: Mental Component Summary, $r=$ Spearman's rank correlation coefficient.

Figure 1. Scatter plots: Left scatter gram exhibits the relationship between PSQI and the OHIP-14, and the Right scatter gram shows the PCS and the MCS scores. 
In this study, a significant positive correlation between the PSQI and the OHIP-14 was observed, indicating that people with low oral health-related QOL exhibit poor sleep quality.

The PSQI provides an index to identify sleep quality and sleep disorders based on a subjective assessment of sleep. It is reported that the PSQI can distinguish the patients with primary insomnia in comparison with healthy subjects [35]. Because it can detect the sleep quality and the symptom of sleep disturbance [27], PSQI is a measure with good sensitivity.

Although the subjects in this study were in a different age group, the findings support previous research reporting poor PSQI scores in persons with periodontal diseases who exhibited low oral health-related QOL [36].

The OHIP-14 measures an individual's subjective perception about his or her oral health condition. Since it is affected by the status of remaining teeth and chewing ability, it was thought to be associated with a subjective perception of well-being, and mental and psychological factors [37]. A survey on perceptions of oral health using the OHIP has reported that mental aspects affect oral conditions [38], and since the mental health-related QOL was high even for those with physical disorders, it is presumed that among elderly people living in the community, some factor that helps them sustain mental health is prevalent. This finding supports those of previous research reporting that even with physical disorders, people who perceive their QOL to be favorable are better able to lessen physical burdens and prevent falls [39]. In addition, an association between sleep quality with bodily pain and vitality has been reported [40], and it is likely that sleep quality affects physical and mental health, thereby affecting QOL in elderly people.

Moreover, among the 8 subscales of the SF-8, the physical health-related QOL comprises "physical functioning (PF)," "role physical (RP)," "bodily pain (BP)," and "general health (GH)," and the mental health-related QOL comprises "vitality (VT)," "social functioning (SF)," "role emotional (RE)," and "mental health (MH)." Among the subjects in this survey, many (31 subjects) had low physical health-related QOL scores, and many (40 subjects) had high mental health-related QOL scores.

Additionally, a negative correlation was confirmed between the physical health components summary scores (PCS) and mental health component summary scores (MCS). These results confirm that some people who have inferior physical health have good mental health condition. Because of this, it was considered that good subjective mental health view is important for living in the community [41].

QOL refers to finding a balance between the body, mind, and spirit in the self, and on establishing and maintaining a harmonious set of relationships within the person's social context and external environment [42]: therefore, self-perception about fulfilment and well-being in life can be considered as an important factor.

Since the total number of subjects in this study $(\mathrm{N}=51)$ was small, there may 
be other factors associated with subjects' poor sleep quality, apart from the oral hygiene condition. However, among the subjects in this study, 23 (45.1\%) were classified in Eichner's classification category $\mathrm{C}$, denoting a complete absence of occlusal support in all four areas, and 17 (33.3\%) in category B, with partially or completely missing occlusal support in four areas, resulting in approximately $80 \%$ of subjects experiencing occlusal support disorders.

Previous survey suggested that oral dryness and the number of teeth may be more important risk factors than aging, lifestyle and comorbidity when considering the dynamics of dysphagia in community-dwelling older adults [43]. Further and future research should determine significant factors that enable elderly people to lead a healthy and happy life in the community, and connect them to the actual support required.

The proportion of elderly people living in target area A for this study exceeded $40 \%$, which is relatively high compared to the Japanese national average of $26.7 \%$ [1]. It was considered that enabling elderly people to live happily while coping with their chronic diseases will not only help reduce medical expenditures, but also create a desirable form of Japanese society in the future.

\section{Conclusion}

In the elderly people with chronic diseases who were 55 years and older and living in the community, low oral health-related QOL (OHIP-14) and poor sleep quality were observed. Moreover, even among subjects with low mental health component summary scores (MCS), there were those who obtained high physical health component summary scores (PCS). Accordingly, appropriate dental treatment and care support that the maintenance of activities including sleeping, and mental health promotion are likely required and remain critically important for elderly people in maintaining an independent lifestyle in the community.

\section{Acknowledgements}

The authors would like to express their gratitude and deep appreciation to the subjects of this study, and all the staff at the Minami Hospital who have helped in many ways.

\section{Conflicts of Interest}

The authors declare no conflict of interest.

\section{References}

[1] Cabinet Office, Government of Japan (2017) Annual Report on the Aging Society 2017. (In Japanese) http://www8.cao.go.jp/kourei/whitepaper/w-2017/html/zenbun/index.html

[2] 8020 Promotion Foundation (2007) Improve Your Health by Preventing Periodontal Disease. (In Japanese) http://www.8020zaidan.or.jp/pdf/kenko/haguki.pdf

[3] Ministry of Health, Labor and Welfare: Japan (2017) Dental Diseases Survey in 
2017. (In Japanese) http://www.mhlw.go.jp/toukei/list/62-28.html

[4] Ministry of Health, Labor and Welfare: Japan (2015) National Health and Nutrition Survey. (In Japanese)

http://www.mhlw.go.jp/file/04-Houdouhappyou-10904750-Kenkoukyoku-Gantaisa kukenkouzoushinka/kekkagaiyou.pdf

[5] Wakai, K., Naito, M., Naito, T., Kojima, M., Nakagaki, H., Umemura, O., Yokota, M., Hanada, N. and Kawamura, T. (2010) Tooth Loss and Intakes of Nutrients and Foods: A Nationwide Survey of Japanese Dentists. Community Dentistry and Oral Epidemiology, 38, 43-49. https://doi.org/10.1111/j.1600-0528.2009.00512.x

[6] Takata, Y., Ansai, T., Awano, S., Sonoki, K., Fukuhara, M., Wakisaka, M. and Takehara, T. (2004) Activities of Daily Living and Chewing Ability in an 80-Year-Old Population. Oral Diseases, 10, 365-368. https://doi.org/10.1111/j.1601-0825.2004.01047.x

[7] Lexomboon, D., Trulsson, M., Wårdh, I. and Parker, M.G. (2012) Chewing Ability and Tooth Loss: Association with Cognitive Impairment in an Elderly Population Study. Journal of the American Geriatrics Society, 60, 1951-1956.

https://doi.org/10.1111/j.1532-5415.2012.04154.x

[8] Ansai, T., Takata, Y., Soh, I., Awano, S., Yoshida, A., Sonoki, K., Hamasaki, T., Torisu, T., Sogame, A., Shimada, N. and Takehara, T. (2010) Relationship between Tooth Loss and Mortality in 80-Year-Old Japanese Community-Dwelling Subject. BMC Public Health, 10, 386. https://doi.org/10.1186/1471-2458-10-386

[9] Inukai, M., John, M.T., Igarashi, Y. and Baba, K. (2010) Association between Perceived Chewing Ability and Oral Health-Related Quality of Life in Partially Dentate Patients. Health and Quality of Life Outcomes, 8, 118. https://doi.org/10.1186/1477-7525-8-118

[10] Akifusa, S., Soh, I., Ansai, T., Hamasaki, T., Takata, Y., Yohida, A., Fukuhara, M., Sonoki, K. and Takehara, T. (2005) Relationship of Number of Remaining Teeth to Health-Related Quality of Life in Community-Dwelling Elderly. Gerodontology, 22, 91-97. https://doi.org/10.1111/j.1741-2358.2005.00059.x

[11] Iinuma, T., Arai, Y., Takayama, M., Takayama, M., Abe, Y., Osawa, Y., Fukumoto, M., Fukui, Y., Shioda, Y., Hirose, N., Komiyama, K. and Gionhaku, N. (2017) Satisfaction with Dietary Life Affects Oral Health-Related Quality of Life and Subjective Well-Being in Very Elderly People. Journal of Oral Science, 59, 207-213. https://doi.org/10.2334/josnusd.16-0414

[12] Yamamoto, T., Kondo, K., Misawa, J., Hirai, H., Nakade, M., Aida, J., Kondo, N., Kawachi, I. and Hirata, Y. (2012) Dental Status and Incident Falls among Older Japanese: A Prospective Cohort Study. BMJ Open, 2, e001262.

https://doi.org/10.1136/bmjopen-2012-001262

[13] Ogawa, T., Ikebe, K., Enoki, K., Murai, S. and Maeda, Y. (2012) Investigation of Oral Opportunistic Pathogens in Independent Living Elderly Japanese. Gerodontology, 29, e229-e233. https://doi.org/10.1111/j.1741-2358.2010.00449.x

[14] Tada, A. and Hanada, N. (2010) Opportunistic Respiratory Pathogens in the Oral Cavity of the Elderly. FEMS Immunology \& Medical Microbiology, 60, 1-17. https://doi.org/10.1111/j.1574-695X.2010.00709.x

[15] Naito, M., Kato, T., Fujii, W., Ozeki, M., Yokoyama, M., Hamajima, N. and Saitoh, E. (2010) Effects of Dental Treatment on the Quality of Life and Activities of Daily Living in Institutionalized Elderly in Japan. Archives of Gerontology and Geriatrics, 50, 65-68. https://doi.org/10.1016/j.archger.2009.01.013

[16] Cornejo, M., Pérez, G., Lima, K.C., Casals-Peidro, E. and Borrell, C. (2013) Oral 
Health-Related Quality of Life in Institutionalized Elderly in Barcelona (Spain). Medicina Oral, Patologia Oral Y Cirugia Bucal, 18, e285-e292. https://doi.org/10.4317/medoral.18280

[17] Dahl, K.E., Wang, N.J., Skau, I. and Ohrn, K. (2011) Oral Health-Related Quality of Life and Associated Factors in Norwegian Adults. Acta Odontologica Scandinavica, 69, 208-214. https://doi.org/10.3109/00016357.2010.549502

[18] Neubauer, D.N. (1999) Sleep Problems in the Elderly. American Family Physician, 59, 2551-2558. http://www.aafp.org/afp/1999/0501/p2551.html

[19] Roffwarg, H.P., Muzio, J.N. and Dement, W.C. (1966) Ontogenic Development of the Human Sleep-Dream Cycle; The Prime Role of Dreaming Sleep in Early Life May Be in the Development of the Central Nervous System. Science, 152, 604-619. https://doi.org/10.1126/science.152.3722.604

[20] Benca, R.M., Obermeyer, W.H., Thisted, R.A. and Gillin, C. (1992) Sleep and Psychiatric Disorders. A Meta-Analysis. Archives of General Psychiatry, 49, 651-668. https://doi.org/10.1001/archpsyc.1992.01820080059010

[21] Ohayon, M.M., Carskadon, M.A., Guilleminault, C. and Vitiello, M.V. (2004) Meta-Analysis of Quantitative Sleep Parameters from Childhood to Old Age in Healthy Individuals: Developing Normative Sleep Values across the Human Lifespan. Sleep, 27, 1255-1273. https://doi.org/10.1093/sleep/27.7.1255

[22] Goldman, S.E., Stone, K.L., Ancoli-Israel, S., Blackwell, T., Ewing, S.K., Boudreau, R., Cauley, J.A., Hall, M., Matthews, K.A. and Newman, A.B. (2007) Poor Sleep Is Associated with Poorer Physical Performance and Greater Functional Limitations in Older Women. Sleep, 30, 1317-1324. https://doi.org/10.1093/sleep/30.10.1317

[23] Malinowska, K.B., Okura, M., Ogita, M., Yamamoto, M., Nakai, T., Numata, T., Tsuboyama, T. and Arai, H. (2016) Effect of Self-Reported Quality of Sleep on Mobility in Older Adults. Geriatrics \& Gerontology International, 16, 266-271. https://doi.org/10.1111/ggi.12468

[24] Lin, T.C. and Liao, Y.C. (2016) The Impact of Sunlight Exposure on the Health of Older Adults. The Journal of Nursing, 63, 116-122.

[25] Kim, M., Yoshida, H., Sasai, H., Kojima, N. and Kim, H. (2015) Association between Objectively Measured Sleep Quality and Physical Function among Community-Dwelling Oldest Old Japanese: A Cross-Sectional Study. Geriatrics \& Gerontology International, 15, 1040-1048. https://doi.org/10.1111/ggi.12396

[26] Doi, Y., Minowa, M., Uchiyama, M., Okawa, M., Kim, K., Shibui, K. and Kamei, Y. (2000) Psychometric Assessment of Subjective Sleep Quality using the Japanese Version of the Pittsburgh Sleep Quality Index (PSQI-J) in Psychiatric Disordered and Control Subjects. Psychiatry Research, 97, 165-172.

https://doi.org/10.1016/S0165-1781(00)00232-8

[27] Buysse, D.J., Reynolds, C.F., Monk, T.H., Berman, S.R. and Kupfer, D.J. (1989) The Pittsburgh Sleep Quality Index: A New Instrument for Psychiatric Practice and Research. Psychiatry Research, 28, 193-213. https://doi.org/10.1016/0165-1781(89)90047-4

[28] Fukuhara, S. and Suzukamo, Y. (2004) Manual of the SF-8 Japanese Version. Institute for Health Outcome and Process Evaluation Research, Kyoto.

[29] Slade, G.D. and Spencer, A.J. (1994) Development and Evaluation of the Oral Health Impact Profile. Community Dent Health, 11, 3-11.

[30] Ikebe, K., Watkins, C.A., Ettinger, R.L., Sajima, H. and Nokubi, T. (2004) Application of Short-Form Oral Health Impact Profile on Elderly Japanese. Gerodontology, 21, 167-176. https://doi.org/10.1111/j.1741-2358.2004.00028.x 
[31] Nakai, N., Sadamori, S., Kawamura, M., Sasahara, H. and Hamada, T. (2004) Bilinguals' Responses to Oral Health Impact Profile (OHIP) Written in English and in Japanese. The Journal of the Japan Prosthodontic Society, 48, 163-172. https://doi.org/10.2186/jjps.48.163

[32] Yoshino, K., Kikukawa, I., Yoda, Y., Watanabe, H., Fukai, K., Sugihara, N. and Matsukubo, T. (2012) Relationship between Eichner Index and Number of Present Teeth. The Bulletin of Tokyo Dental College, 53, 37-40. https://doi.org/10.2209/tdcpublication.53.37

[33] Vitiello, M.V., Moe, K.E. and Prinz, P.N. (2002) Sleep Complaints Cosegregate with Illness in Older Adults: Clinical Research Informed by and Informing Epidemiological Studies of Sleep. Journal of Psychosomatic Research, 53, 555-559.

https://doi.org/10.1016/S0022-3999(02)00435-X

[34] Ministry of Health, Labour and Welfare (2017) Health Japan 21 (the Second Term). http://www.mhlw.go.jp/seisakunitsuite/bunya/kenkou_iryou/kenkou/kenkounippo $\underline{\mathrm{n} 21 / \mathrm{en} /}$

[35] Backhaus, J., Junghanns, K., Broocks, A., Riemann, D. and Hohagen, F. (2002) Test-Retest Reliability and Validity of the Pittsburgh Sleep Quality Index in Primary Insomnia. Journal of Psychosomatic Research, 53, 737-740. https://doi.org/10.1016/S0022-3999(02)00330-6

[36] Almoznino, G., Zini, A., Sharav, Y., Shahar, A., Zlutzky, H., Haviv, Y., Lvovsky, A. and Aframian, D.J. (2015) Sleep Quality in Patients with Dental Anxiety. Journal of Psychiatric Research, 61, 214-222. https://doi.org/10.1016/j.jpsychires.2014.11.015

[37] Lee, I.C., Shieh, T.Y., Yang, Y.H., Tsai, C.C. and Wang, K.H. (2007) Individuals' Perception of Oral Health and Its Impact on the Health-Related Quality of Life. Journal of Oral Rehabilitation, 34, 79-87. https://doi.org/10.1111/j.1365-2842.2006.01694.x

[38] Navabi, N., Farnudi, H., Rafiei, H. and Arashlow, M.T. (2012) Orthodontic Treatment and the Oral Health-Related Quality of Life of Patients. Journal of Dentistry, 9, 247-254. http://pubmedcentralcanada.ca/pmcc/articles/PMC3484829/

[39] Bowling, A., Seetai, S., Morris, R. and Ebrahim, S. (2007) Quality of Life among Older People with Poor Functioning. The Influence of Perceived Control over Life. Age and Ageing, 36, 310-315. https://doi.org/10.1093/ageing/afm023

[40] Sampaio, R.A., Sewo Sampaio, P.Y., Yamada, M., Tsuboyama, T. and Arai, H. (2014) Self-Reported Quality of Sleep Is Associated with Bodily Pain, Vitality and Cognitive Impairment in Japanese Older Adults. Geriatrics \& Gerontology International, 14, 628-635. https://doi.org/10.1111/ggi.12149

[41] Slade, M. (2010) Mental Illness and Well-Being: The Central Importance of Positive Psychology and Recovery Approaches. BMC Health Services Research, 10, 26. https://doi.org/10.1186/1472-6963-10-26

[42] Albrecht, G.L. and Devlieger, P.J. (1999) The Disability Paradox: High Quality of Life against All Odds. Social Science \& Medicine, 48, 977-988. https://doi.org/10.1016/S0277-9536(98)00411-0

[43] Inui, A., Takahashi, I., Kurauchi, S., Soma, Y., Oyama, T., Tamura, Y., Noguchi, T., Murashita, K., Nakaji, S. and Kobayashi, W. (2017) Oral Conditions and Dysphagia in Japanese, Community-Dwelling Middle- and Older-Aged Adults, Independent in Daily Living. Clinical Interventions in Aging, 12, 515-521. https://doi.org/10.2147/CIA.S132637 